\title{
The Steroid Spectrum During and After Quitting Smoking
}

\author{
H. JANDIKOVA ${ }^{1}$, M. DUSKOVA ${ }^{1}$, K. SIMUNKOVA ${ }^{1,2}$, B. RACZ ${ }^{1}$, M. HILL ${ }^{1}$, \\ E. KRALIKOVA ${ }^{3,4}$, K. VONDRA ${ }^{1}$, L. STARKA ${ }^{1}$
}

${ }^{1}$ Institute of Endocrinology, Prague, Czech Republic, ${ }^{2}$ Third Department of Medicine, First Faculty of Medicine, Charles University and General University Hospital, Prague, Czech Republic, ${ }^{3}$ The Center for Tobacco Dependence, Third Medical Department - Department of Endocrinology and Metabolism, First Faculty of Medicine, Charles University and General University Hospital, Prague, Czech Republic, ${ }^{4}$ Institute of Hygiene and Epidemiology, First Faculty of Medicine, Charles University and General University Hospital, Prague, Czech Republic

Received May 6, 2015

Accepted May 20, 2015

\section{Summary}

Addiction to tobacco results in an imbalance of endocrine homeostasis in both sexes. This can also have impacts on fertility problems. The male reproductive system is less susceptible than that of females, with a worsening spermiogram in smokers, the most cited effect in the literature. However, the literature is inconsistent as to the effects of smoking on steroid hormone levels in men, and there is very little data on the effects of quitting smoking in men. In this study we followed 76 men before quitting smoking, and then after 6,12 , and 24 weeks and 1 year of abstinence. We measured basic anthropomorphic data and steroid hormone levels along with steroid neuroactive metabolites using GC-MS. We demonstrate lower androgen levels in men who smoke, and these changes worsened after quitting smoking. There was a drop in SHBG already in the first week of non-smoking, and levels continued to remain low. Male smokers have lower androgen levels compared to non-smokers. The lower the initial level of androgen, the lower the likelihood of success in quitting smoking. Changes in steroid hormones proved to be a promising marker for the prediction of success in quitting smoking.

\section{Key words}

Men • Smoking cessation • Prediction • SHBG • Testosterone

\section{Corresponding author}

M. Dušková, Institute of Endocrinology, Národní 8, 11694 Prague 1, Czech Republic. E-mail: mduskova@endo.cz

\section{Introduction}

Smoking is the most widespread addiction worldwide. Addiction to tobacco is a chronic, recurring and fatal illness, which on average shortens the lives of half the smokers in the Czech Republic by 15 years. In both the Czech Republic and Europe as a whole, smoking is the cause of every fifth death, mainly through cancer, cardiovascular and chronic pulmonary diseases, but also affecting other diseases representing all clinical disciplines. There are 18,000 yearly deaths in the Czech Republic, or 50 daily, caused by smoking, and of those about 10,000 are in their productive years (http:// www.ctsu.ox.ac.uk/deathsfromsmoking/countries.html).

Tobacco smoke is a dynamic complex of more than 4000 gasses and particles. It contains approximately 100 tumor-promoting carcinogens (for instance dibenzanthracene, ens-a-pyrene, dimethlynitrosamine, diethylnitrosamine, vinylchloride, hydrazine, arsenic) or suspected carcinogens. Other components include mutagens, allergens, toxic compounds, a high percentage of carbon monoxide, and about 700 additives. These affect a wide range of processes in the body including the secretion of hormones.

Many studies have demonstrated the ability of nicotine to change the hormonal homeostasis of both men and women. Smoking influences the hypophyseal, thyroid, adrenal, testicular and ovarian functions, calcium metabolism, and the activity of insulin (see review Stárka et al. 2005). 
The most common effects associated with smoking are erectile dysfunction (Corona et al. 2005, Natalia et al. 2005) and especially spermiogram quality (Shaarawy and Mahmoud 1982, Patterson et al. 1990, Istvan et al. 1994, Trummer et al. 2002). There are inconsistent results in the literature on the effects of smoking on steroid hormone levels, and the effects of quitting smoking have been addressed by only a few studies.

In studies following changes in steroids due to smoking, both increases (Dai et al. 1988) and decreases (Briggs 1973) have been reported, as well as data showing no effect of smoking on the total levels of testosterone (Barrett-Connor and Khaw 1987). These inconsistent results arise from various factors. One is the difficulty and non-standardization of laboratory methods. Another arises from not respecting the fact that testosterone levels vary during the day. Testosterone has a circadian rhythm with levels peaking between 6:00-8:00 and minimum concentrations between 18:00-20:00. An additional difficulty is that most studies on the effects of smoking on hormone levels do not discriminate between free and bound testosterone. There is a significant proportion of testosterone in the blood bound to SHBG $(65-80 \%)$, with the remainder bound to albumin (20-40\%) or freely circulating (1-3\%). It is this binding capacity of plasma that is the main cause of inconsistent results. Another issue is that androgens can be active even bound to SHBG through binding to the SHBG receptor. It is thus not possible to simply consider bound testosterone to be biologically inactive. Most studies that have also worked with SHBG levels agree that they are higher in smokers (Field et al. 1994, English et al. 2001, Kapoor and Jones 2005).

The mechanism by which smoking can increase testosterone levels is not clear. In addition to the hypothesis that it is a secondary affect to the increase in SHBG in smokers, there are also other theories. In a study giving an aromatase inhibitor (anastrozole) to older men with low testosterone levels, increases in levels of both total and free testosterone were demonstrated (Leder et al. 2004).

English et al. (2001) showed that higher total testosterone in smokers is contingent on higher SHBG, and that only SHBG levels correlated with serum nicotine levels. In contrast, Svartberg and Jorde (2007) found a positive association between testosterone levels and smoking even when adjusting for SHBG levels. They found significantly higher levels of total (by $15 \%$ ) and free (by $13 \%$ ) testosterone in smokers compared to men who had never smoked. In fact both values significantly increased with the number of cigarettes smoked per day. The authors concluded that smoking even masks borderline hypogonadism in men (Svartberg and Jorde 2007). Dai et al. (1988) also demonstrated a positive correlation between smoking and serum levels of androstendione as well as free and total testosterone, irrespective of age, weight, alcohol consumption and blood pressure. Levels of estrogen, however, did not differ between smokers and non-smokers.

Field et al. (1994) found significantly higher levels of SHBG, but non-significant changes in the levels of testosterone bound to albumin. They were inclined to the idea that higher levels of total testosterone are secondary to higher SHBG. It seems that testosterone levels are more sensitively influenced by the binding capacity of the plasma than to a direct effect of smoking on androgens.

At the same time there are also studies showing the opposite - lower testosterone levels as an influence of smoking. These studies are based on experimental models. Meikle et al. (1988) studied the influence of nicotine and cotinine on the enzymatic capacity of dog prostates. They found that they act as competitive inhibitors of 3-alpha-hydroxysteroid dehydrogenases (enzymes that convert dihydrotestosterone to 3 alphaandrostanediol) and result in an accumulation of DHT. One result could be the alteration of androgens acting in various tissues such as the epidermis, skin, and prostate (Meikle et al. 1988). Another study followed the effects of chronic smoking on androgen metabolism in dogs, and showed lower activities of 7 alpha-hydroxylases and stimulated activities of hepatic 6 beta-hydroxylases. Serum levels of testosterone were lower and LH levels higher than in controls. These results indicate that chronic smoking increases the intra-hepatic metabolism of testosterone (Mittler et al. 1983).

Patterson et al. (1990) showed that nicotine changes the steroidogenesis of Leydig cells in mice. Chronic doses of nicotine led to lower fertility in male rats. Nicotine also inhibits the pulse secretion of $\mathrm{LH}$ in rats, leading to the inhibition of LH-stimulated steroidogenesis.

Some studies of male smokers have confirmed this effect of nicotine. Shaarawy and Mahmoud (1982) demonstrated significantly lowered levels of total testosterone in smokers versus non-smokers, but did not discriminate between levels of free, bioactive testosterone 
or SHBG levels. They also studied spermiograms, and found that there was significantly lower initial sperm motility in smokers and that the proportion of abnormal forms of spermatozoa was significantly higher (Shaarawy and Mahmoud 1982).

Other studies have shown lower concentrations of urinary testosterone in male smokers compared to age and BMI matched non-smokers (Olayaki et al. 2008).

Mendelson et al. (2003) studied the effects of cigarette smoking (with both high and low nicotine levels) on hormone levels in male smokers. The acute effect of smoking was lowered testosterone levels, though the decrease was not significant even when comparing values after smoking high versus low-nicotine cigarettes. LH levels were significantly higher, which should have led to increased testosterone levels. This was the case for instance in the study of Mello et al. (2000), where monkeys were given opioid antagonists that stimulated LH, followed after 40-50 $\mathrm{min}$ by increased testosterone levels. Mendelson et al. (2003) hypothesized that in their study the reactive increase in testosterone did not occur because of an insufficiently strong stimulation by $\mathrm{LH}$ after smoking high-nicotine cigarettes, likely because the bioactivity of these specific LH isoforms were lower.

At the Institute of Endocrinology we first demonstrated, that the influence of smoking cessation on male reproductive system, in terms of hormonal homeostasis, has little significance on testosterone, DHEA and cortisol (Hruškovičová et al. 2013). However, there results inspired us to focus on a more detailed study of steroid metabolome in men. Thus, we extended the measurement to 37 steroids and steroid polar conjugates. In line with the latest trends, we applied a new method for hormone level measurement. Application of the GC-MS method delivered more accurate results and revealed differences between tested groups that have not been identified when employing the RIA method in earlier research.

\section{Methods}

In this study, we enrolled 76 men that had decided to quit smoking and sought medical help in the Center for Tobacco Addiction at the General Faculty Hospital in Prague. The average age of these smokers was $39.3( \pm 11.5)$ years with an average BMI of 26.52 $( \pm 3.8) \mathrm{kg} / \mathrm{m}^{2}$. At the start of the study they smoked an average of $24( \pm 10)$ cigarettes daily. During their first visit they all responded to a detailed medical history, had basic anthropomorphic data measured, and had a baseline sampling taken while still smokers. Enrollment criteria were good health, not undergoing treatment for any serious chronic disease, and not using any medicine that could influence steroidogenesis. The local Ethics Committee approved the study and all patients signed an informed consent form before taking part in the study.

In addition to the smokers, we enrolled a control group of 20 men, age and BMI matched, who were nonsmokers and who had never smoked in the past. This control group had an average age of $40.1( \pm 13.3)$ years and average BMI of $25.9( \pm 4.1) \mathrm{kg} / \mathrm{m}^{2}$.

The study was designed to be prospective: further sampling was performed according to protocol after 6 weeks, 12 weeks, 24 weeks, and 48 weeks of nonsmoking. In addition they were treated at the Center for Tobacco Addiction. Abstinence was controlled by measuring $\mathrm{CO}$ in exhaled air and urinary cotinine levels. While quitting smoking, the men were allowed to use nicotine substitutes in the form of gum or patches.

We divided the smokers into three groups based on their success in quitting. The first group consisted of those who did not quit smoking at all (group S-, 34 men). The second group of 16 men was able to quit smoking for at least 6 weeks (group $\mathrm{S} \pm$ ). The third group of 26 men was successful in quitting smoking for an entire year (group $\mathrm{S}+$ ). We followed differences in the steroid spectrum of these individual groups and compared them with controls.

\section{Steroid analyses}

\section{Steroids measured by GC/MS method}

The levels of unconjugated steroids and steroid polar conjugates after hydrolysis were concomitantly measured in cubital vein blood using the GC-MS method (Hill et al. 2010).

In brief, free steroids were extracted from plasma by diethyl-ether; steroid conjugates were hydrolyzed and extracted. The resulting residues were derivatized by methoxyamine hydrochloride and analyzed by GC/MS as follows.

\section{Chemicals and reagents}

Steroids were purchased from Steraloids (Newport, RI, USA), Sylon B from Supelco (Bellefonte, PA, USA), methoxylamine hydrochloride from Sigma (St. Louis, MO, USA) and solvents from Merck (Darmstadt, Germany). 


\section{Instruments}

Measurements of steroid levels were done on a GCMS-QP2010 Plus system by Shimadzu (Kyoto, Japan) consisting of a gas chromatograph equipped with automatic flow control, an AOC-20s autosampler, and a single quadrupole detector with an adjustable electron voltage of 10-195 V. A capillary column with a medium polarity RESTEK Rxi (diameter $0.25 \mathrm{~mm}$, length $15 \mathrm{~m}$, film thickness $0.1 \mu \mathrm{m})$ was used for analyses. Electronimpact ionization with electron voltage fixed at $70 \mathrm{~V}$ and emission current set to $160 \mu \mathrm{A}$ was used. The temperatures of the injection port, ion source and interface were maintained at $220^{\circ} \mathrm{C}, 300^{\circ} \mathrm{C}$, and $310^{\circ} \mathrm{C}$, respectively. Analyses were carried out in the splitless mode with a constant linear velocity of the carrier gas (He), which was maintained at $60 \mathrm{~cm} / \mathrm{s}$. The septum purge flow was set at $3 \mathrm{ml} / \mathrm{min}$. The samples were injected using the high pressure mode $(200 \mathrm{kPa})$, which was maintained for $1 \mathrm{~min}$. The detector voltage was set to $1.4 \mathrm{kV}$.

17-hydroxy-pregnenolone was measured by the RIA method, and 17-hydroxy-pregnenolone sulfate by the same method after hydrolysis (Hill et al. 1999). Estradiol was measured using a RIA kit from Orion (Finland) and 17-hydroxy-progesterone using a kit from Immunotech (France). Cortisol was measured using a RIA kit from Orion (Finland). Sex hormones bound to globulin (SHBG) were measured by the IRMA method (Orion, Finland). Kits from Immunotech (France) were used to measure LH and FSH (IRMA kit). The free androgen index (FAI) was calculated as the ratio of testosterone/SHBG x 100.

\section{Statistical analyses}

The Mann-Whitney test was used to compare levels of steroids, gonadotropin, and SHBG between smokers and controls. Changes in the levels of steroids, gonadotropin, and SHBG in smokers during the study were measured with repeated ANOVA models. Differences in levels of steroids, gonadotropin, and SHBG at the start of the study between the control group and smoking groups divided based on their success of quitting were evaluated by the robust Kruskal-Wallis test followed by robust Dunn's multiple comparison.

Table 1. Hormone levels lower in smokers compared to controls. Levels of measured parameters in smokers during the baseline sampling before starting quitting smoking and in controls (medians and quartiles). Smokers were divided into three groups based on their success in quitting smoking: group S+ were those completely quitting smoking; S \pm were those who quit for at least 6 weeks and then re-started; S- were those who did not quit at all.

\begin{tabular}{|c|c|c|c|c|}
\hline Analyte/Group & Control & $\mathbf{S}+$ & $\mathbf{S} \pm$ & S- \\
\hline 16 $\alpha$-hydroxy-pregnenolone & $0.448(0.23 ; 0.684)$ & $0.417(0.318 ; 0.518)$ & $0.25(0.189 ; 0.45)$ & $0.24(0.185 ; 0.444)$ \\
\hline Testosterone & $20.5(13.4 ; 26.6)$ & $18.3(13.5 ; 29)$ & $17.9(15.2 ; 24.7)$ & $14.4(11.3 ; 17.3)$ \\
\hline Androsterone sulfate & $1940(1080 ; 2640)$ & $1560(899 ; 1980)$ & $953(773 ; 1600)$ & $1440(1290 ; 1750)$ \\
\hline $\begin{array}{l}5 \alpha \text {-androstane- } 3 \alpha \\
17 \beta \text {-diol sulfate }\end{array}$ & $15.2(6.95 ; 73.6)$ & $5(2.45 ; 15.4)$ & $10.8(2.12 ; 34)$ & $5.64(3.75 ; 11.3)$ \\
\hline $\begin{array}{l}5 \alpha \text {-androstane- } 3 \beta \text {, } \\
17 \beta \text {-diol sulfate }\end{array}$ & $151(75.8 ; 226)$ & $69.3(49.6 ; 99.2)$ & $142(90.6 ; 353)$ & $116(79.2 ; 221)$ \\
\hline $\begin{array}{l}\text { 5-androstene- } 3 \beta, 7 \alpha \text {, } \\
17 \beta \text {-triol }\end{array}$ & $0.174(0.111 ; 0.226)$ & $0.0986(0.0705 ; 0.161)$ & $0.0903(0.0481 ; 0.195)$ & $0.074(0.0541 ; 0.12)$ \\
\hline $\begin{array}{l}\text { 5-androstene- } 3 \beta, 7 \beta \text {, } \\
17 \beta \text {-triol }\end{array}$ & $0.215(0.125 ; 0.296)$ & $0.138(0.123 ; 0.185)$ & $0.146(0.0977 ; 0.244)$ & $0.107(0.0863 ; 0.175)$ \\
\hline 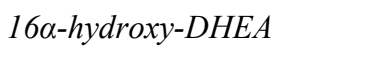 & $0.117(0.0622 ; 0.173)$ & $0.103(0.0532 ; 0.134)$ & $0.0519(0.0188 ; 0.0934)$ & $0.0421(0.0178 ; 0.061)$ \\
\hline 7 $\beta$-hydroxy-DHEA & $0.648(0.371 ; 1.06)$ & $0.562(0.387 ; 0.683)$ & $0.456(0.354 ; 1.03)$ & $0.389(0.256 ; 0.681)$ \\
\hline
\end{tabular}

Values are given as medians and quartiles (nmol/l). Significance level $\mathrm{P}<0.05$.

\section{Results}

One year after quitting smoking, we found statistically significant higher BMI levels. The average
BMI at the start of the study of men successfully quitting smoking was $26.2 \mathrm{~kg} / \mathrm{m}^{2}( \pm 3.3)$, and after one year of nonsmoking increased to $28.7 \mathrm{~kg} / \mathrm{m}^{2}( \pm 3.7)$. Therefore, men successful at quitting smoking gained an average of 
$6.8( \pm 3.5) \mathrm{kg}$. At the start of the study these men smoked $23.5( \pm 9.6)$ cigarettes daily, which was not statistically different than the average for the whole group of smokers.

Smokers, irrespective of their success in quitting smoking, did not have differences in most followed hormone levels compared to non-smokers. We did, however, find lower testosterone levels in smokers, as well as in some other androgens (16 $\alpha$-hydroxy-pregnenolone, androsterone sulfate, $5 \alpha$-androstane- $3 \alpha, 17 \beta$-diol sulfate, $5 \alpha$-androstane-3 $\beta, 17 \beta$-diol sulfate, 5 -androstene$3 \beta, 7 \alpha, 17 \beta$-triol, $\quad 5$-androstene-3 $\beta, 7 \beta, \quad$ 17 $\beta$-triol, $16 \alpha$-hydroxy-DHEA, and $7 \beta$-hydroxy-DHEA) (Table 1).

Levels of FSH were in line with these results. We show the data divided by sub-groups to better illustrate individual groups. However, results were only significant when smokers were evaluated as a whole.

The group of men who successfully quit smoking was evaluated for the effect of non-smoking on the steroid spectrum. After of year of non-smoking, there was a statistically significant drop in SHBG levels, which decreased already after 6 weeks of non-smoking and were then stable (Table 2).

Table 2. Levels of SHBG (nmol/l), which significantly declined after quitting smoking during the first 6 weeks, and further remained stable, in males successful in quitting smoking. The period of following was 1 year.

\begin{tabular}{lc}
\hline Period & SHBG \\
\hline While smoking & $27.2(16.9 ; 36.2)$ \\
6 weeks of non-smoking & $21.2(15.5 ; 26)$ \\
3 months of non-smoking & $22.1(16.3 ; 28.1)$ \\
6 months of non-smoking & $19.5(15 ; 24.4)$ \\
12 months of non-smoking & $20.5(12.6 ; 31.1)$ \\
\hline
\end{tabular}

Values are given as medians and quartiles. Significance level $\mathrm{P}<0.05$.

Testosterone and some other androgens (pregnenolone sulfate, 20 $\alpha$-dihydropregnenolone, $16 \alpha$-hydroxy-pregnenolone, allopregnanolone, isopregnanolone sulfate, 5-androstene-3 $\beta, 17 \beta$-diol, androsterone, androsterone sulfate, epietiocholanolone sulfate, $5 \alpha$-androstane- $3 \alpha, 17 \beta$-diol, 16 $\alpha$-hydroxy-DHEA sulfate, $7 \alpha$-hydroxy-DHEA, $7 \beta$-hydroxy-DHEA) continuously decreased during the entire first year of non-smoking (Table 3).

Changes in SHBG and testosterone did not correlate with BMI. Levels of testosterone and BMI changed continuously throughout the year. There was a change in SHBG during the first 6 weeks, but then values did not change. This is likely a direct effect of quitting smoking, reflecting the complex influences of smoking.

Most steroid hormones including adrenaline steroids remained unchanged during quitting smoking. From the baseline sampling, we attempted to identify possible markers that would be predictive for the success in quitting among the three groups of smokers. The levels of testosterone, 16 $\alpha$-hydroxy-pregnenolone, 16 $\alpha$ hydroxy-DHEA, $7 \alpha$-hydroxy-DHEA, 7 $\beta$-hydroxy-DHEA, 5 -androstene-3 $\beta, 7 \alpha, 17 \beta$-triol and 5-androstene$3 \beta, 7 \beta, 17 \beta$-triol were associated with success in quitting smoking: the lower the level of these steroids, the lower the likelihood that quitting smoking would be successful (Table 4).

\section{Discussion}

From the results of our baseline measurements of smokers it is clear that smokers have lower levels of testosterone than non-smokers. These findings correspond with those from other studies (Shaarawy and Mahmoud 1982, Mittler et al. 1983, Meikle et al. 1988, Patterson et al. 1990, Olayaki et al. 2008). In line with these lower levels of testosterone, we also found higher FSH levels compared to controls. However, the large majority of neuroactive steroids showed no differences.

Only a few studies have focused on the influence of quitting smoking on levels of steroid hormones. Laaksonen et al. (2005) followed male smokers and described changes in steroidogenesis after lowering the number of cigarettes smoked. At the beginning of that study, both total and free testosterone levels were higher in smokers compared to non-smokers. In the subsequent 13 years they were evaluated, there was a clear association with lowering the number of cigarettes smoked and a significant decline in testosterone, with an increased risk of hypogonadism, defined by levels of total and free testosterone, and increased waist measurement compared to men who continued to smoke without restriction. In agreement with this study, we found lower levels of testosterone after a year of non-smoking.

In the discussion of their study, Laaksonen et al. (2005) predict that lowered testosterone and the increased risk of hypogonadism are related with the increase in weight and waist measurement in men who lowered the number of cigarettes smoked daily or who quit completely (Laaksonen et al. 2005). 


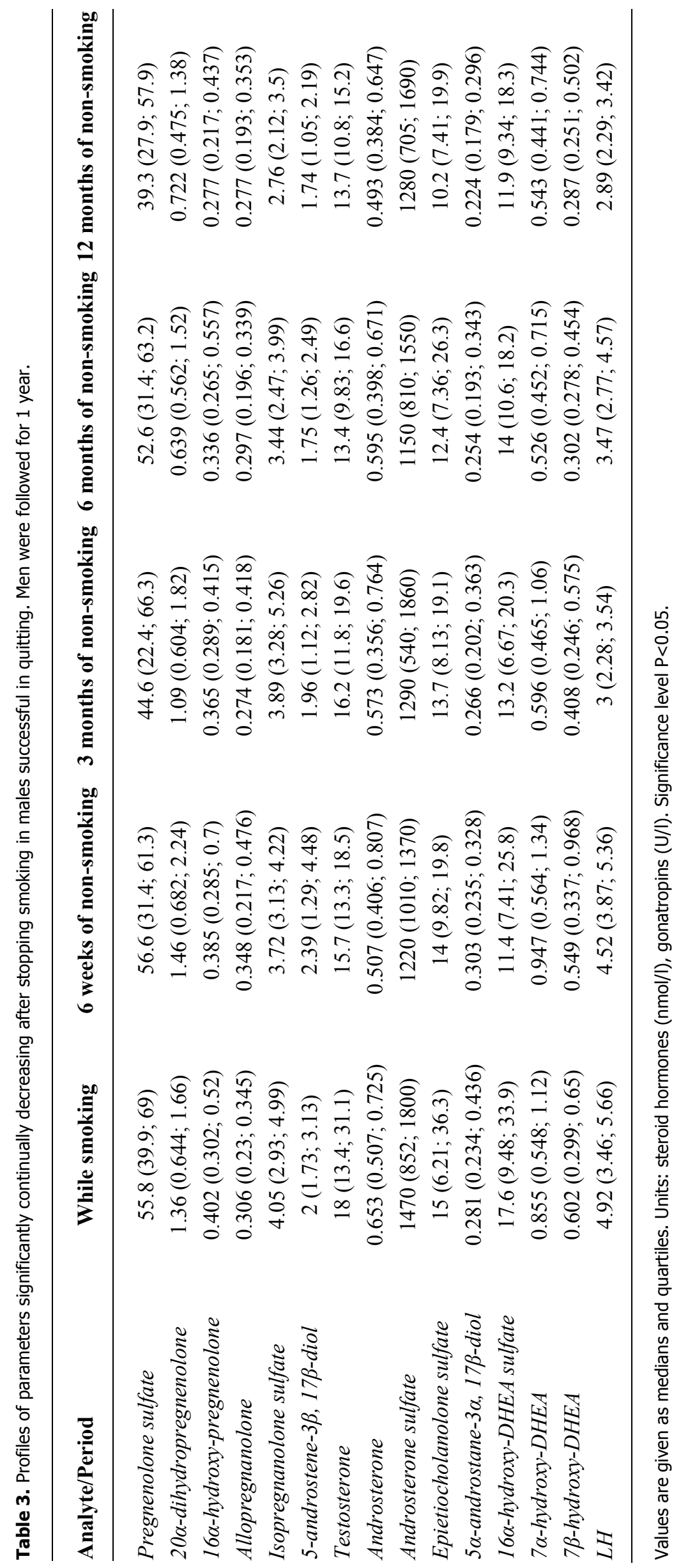


Table 4. Predicting the success of quitting smoking in men. Smokers were divided into three groups based on their success in quitting smoking: group S+ were those completely quitting smoking; $\mathrm{S} \pm$ were those who quit for at least 6 weeks and then re-started; S- were those who did not quit at all.

\begin{tabular}{|c|c|c|c|}
\hline Analyte/Group & $\mathbf{S}+$ & $\mathbf{S} \pm$ & S- \\
\hline 16 $\alpha$-hydroxy-pregnenolone & $0.417(0.318 ; 0.518)$ & $0.25(0.189 ; 0.45)$ & $0.24(0.185 ; 0.444)$ \\
\hline Testosterone & $18.3(13.5 ; 29)$ & $17.9(15.2 ; 24.7)$ & $14.4(11.3 ; 17.3)$ \\
\hline $16 \alpha-h y d r o x y-D H E A$ & $0.103(0.0532 ; 0.134)$ & $0.0519(0.0188 ; 0.0934)$ & $0.0421(0.0178 ; 0.061)$ \\
\hline 7 $\beta$-hydroxy-DHEA & $0.562(0.387 ; 0.683)$ & $0.456(0.354 ; 1.03)$ & $0.389(0.256 ; 0.681)$ \\
\hline 5-androstene- $3 \beta, 7 \alpha, 17 \beta$-triol & $0.0986(0.0705 ; 0.161)$ & $0.0903(0.0481 ; 0.195)$ & $0.074(0.0541 ; 0.12)$ \\
\hline 5-androstene- $3 \beta, 7 \beta, 17 \beta$-triol & $0.138(0.123 ; 0.185)$ & $0.146(0.0977 ; 0.244)$ & $0.107(0.0863 ; 0.175)$ \\
\hline
\end{tabular}

Values are given as medians and quartiles ( $\mathrm{nmol} / \mathrm{l})$. Significance level $\mathrm{P}<0.05$.

In fact, some large cohort studies have shown that overweight men have a better chance at being successful in quitting smoking than those with normal weight (Godtfredsen et al. 2001, Twardella et al. 2006). We searched for similar relationships in our group of smoking males, but higher BMI at the beginning of our study did not predict for greater success in quitting smoking.

However, change of weight did not correlate with lower testosterone in our study. In addition, SHBG changed only during the first 6 weeks, while androgens continuously declined. The mechanisms are clearly different - again pointing to the complex effects of smoking.

Along with decreasing the number of cigarettes smoked or completely quitting there is a clear association with gaining weight, which is caused by many factors. From our data, which agree with similar studies, there is even a lowering in testosterone level. At first glance it seems that quitting smoking has a negative impact. However, Clair et al. (2013) performed a prospective cohort study that demonstrated lowered cardiovascular risk in patients (both male and female) without diabetes after quitting smoking. Gaining weight as a result of quitting smoking did not modify this relationship (Clair et al. 2013), confirming that in the end quitting smoking has beneficial effects.

We present unique data from a prospective study on the development of the steroid metabolome in chronic smokers with strong addiction to tobacco, from the period of active smoking to after one year of abstinence. Changes to the steroid metabolome were shown to be possible markers for the prediction of success in quitting smoking. This finding, however, also leads to a number of further questions regarding this complex issue.

\section{Conflict of Interest}

There is no conflict of interest.

\section{Acknowledgements}

This work was supported by the project MZ CR for conceptual development of research organization 00023761 (Institute of Endocrinology, Prague, Czech Republic) and by the grant 16-27925A.

\section{References}

BARRETT-CONNOR E, KHAW KT: Cigarette smoking and increased endogenous estrogen levels in men. $A m J$ Epidemiol 126: 187-192, 1987.

BRIGGS MH: Cigarette smoking and infertility in men. Med J Aust 1: 616-617, 1973.

CLAIR C, RIGOTTI NA, PORNEALA B, FOX CS, D'AGOSTINO RB, PENCINA MJ, MEIGS JB: Association of smoking cessation and weight change with cardiovascular disease among adults with and without diabetes. JAMA 309: 1014-1021, 2013.

CORONA G, MANNUCCI E, PETRONE L, RICCA V, MANSANI R, CILOTTI A, BALERCIA B, CHIARINI V, GIOMMI R, FORTI G, MAGGI M: Psychobiological correlates of smoking in patients with erectile dysfunction. Int J Impot Res 17: 527-534, 2005.

DAI WS, GUTAI JP, KULLER LH, CAULEY JA: Cigarette smoking and serum sex hormones in men. Am $J$ Epidemiol 128: 796-805, 1988. 
ENGLISH KM, PUGH PJ, PARRY H, SCUTT NE, CHANNER KS, JONES TH: Effect of cigarette smoking on levels of bioavailable testosterone in healthy men. Clin Sci (Lond) 100: 661-665, 2001.

FIELD AE, COLDITZ GA, WILLETT WC, LONGCOPE C, MCKINLAY JB: The relation of smoking, age, relative weight, and dietary intake to serum adrenal steroids, sex hormones, and sex hormone-binding globulin in middle-aged men. J Clin Endocrinol Metab 79: 1310-1316, 1994.

GODTFREDSEN NS, PRESCOTT E, OSLER M, VESTBO J: Predictors of smoking reduction and cessation in a cohort of danish moderate and heavy smokers. Prev Med 33: 46-52, 2001.

HILL M, HAMPL R, LUKAC D, LAPCIK O, POUZAR V, SULCOVA J: Elimination of cross-reactivity by addition of an excess of cross-reactant for radioimmunoassay of 17alpha-hydroxy-pregnenolone. Steroids 64: 341-355, 1999.

HILL M, PARIZEK A, CIBULA D, KANCHEVA R, JIRASEK JE, JIRKOVSKA M, VELIKOVA M, KUBATOVA J, KLIMKOVA M, PASKOVA A, ZIZKA Z, KANCHEVA L, KAZIHNITKOVA H, ZAMRAZILOVA L, STARKA L: Steroid metabolome in fetal and maternal body fluids in human late pregnancy. $J$ Steroid Biochem Mol Biol 122: 114-132, 2010.

HRUSKOVICOVA H, DUSKOVA M, SIMUNKOVA K, HILL M, POSPISILOVA H, RACZ B, KRALIKOVA E, VONDRA K, STARKA L: Effects of smoking cessation on hormonal levels in men. Physiol Res 62: 67-73, 2013.

ISTVAN JA, BUIST AS, HESS DL, VOELKER H: Relationship of smoking cessation and nicotine gum use to salivary androstenedione and testosterone in middle-aged men. Metabolism 44: 90-95, 1994.

KAPOOR D, JONES TH: Smoking and hormones in health and endocrine disorders. Eur J Endocrinol 152: 491-499, 2005.

LAAKSONEN DE, NISKANEN L, PUNNONEN K, NYYSSONEN K, TUOMAINEN TP, VALKONEN VP, SALONEN JT: The metabolic syndrome and smoking in relation to hypogonadism in middle-aged men: a prospective cohort study. J Clin Endocrinol Metab 90: 712-719, 2005.

LEDER BZ, ROHRER JL, RUBIN SD, GALLO J, LONGCOPE C: Effects of aromatase inhibition in elderly men with low or borderline-low serum testosterone levels. J Clin Endocrinol Metab 89: 1174-1180, 2004.

MEIKLE AW, LIU XH, TAYLOR GN, STRINGHAM JD: Nicotine and cotinine effects on 3 alpha hydroxysteroid dehydrogenase in canine prostate. Life Science 43: 1845-1850, 1988.

MELLO NK, MENDELSON JH, KELLY M: Acute effects of nalmefene on LH, prolactin, and testosterone in male rhesus monkeys. Pharmacol Biochem Behav 66: 275-283, 2000.

MENDELSON JH, SHOLAR MB, MUTSCHLER NH, JASZYNA-GASIOR M, GOLETIANI NV, SIEGEL AJ, MELLO NK: Effects of intravenous cocaine and cigarette smoking on luteinizing hormone, testosterone, and prolactin in men. J Pharmacol Exp Ther 307: 339-348, 2003.

MITTLER JC, POGACH L, ERTEL NH: Effects of chronic smoking on testosterone metabolism in dogs. J Steroid Biochem 18: 759-763, 1983.

NATALI A, MONDAINI N, LOMBARDI G, DEL POPOLO G, RIZZO M: Heavy smoking is an important risk factor for erectile dysfunction in young men. Int J Impot Res 17: 227-230, 2005.

OLAYAKI LA, EDEOJA EO, JIMOH OR, GHAZAL OK, OLAWEPO A, JIMOH AG, BILIAMINU SA: Effects of cigarette smoking on urinary testosterone excretion in men. Biokemistri 20: 29-32, 2008.

PATTERSON TR, STRINGHAM JD, MEIKLE AW: Nicotine and cotinine inhibit steroidogenesis in mouse Leydig cells. Life Sci 46: 265-272, 1990.

SHAARAWY M, MAHMOUD KZ: Endocrine profile and semen characteristics in male smokers. Fertil Steril 38: 255-257, 1982.

STÁRKA L, HILL M, KRÁLÍKOVÁ E: Smoking and endocrine system (in Czech). DMEV 8: 180-186, 2005.

SVARTBERG J, JORDE R: Endogenous testosterone levels and smoking in men. The fifth Tromsø study. Int J Androl 30: 137-143, 2007.

TRUMMER H, HABERMANN H, HAAS J, PUMMER K: The impact of cigarette smoking on human semen parameters and hormones. Hum Reprod 17: 1554-1559, 2002.

TWARDELLA D, LOEW M, ROTHENBACHER D, STEGMAIER C, ZIEGLER H, BRENNER H: The impact of body weight on smoking cessation in German adults. Prev Med 42: 109-113, 2006. 